\title{
Novel Agents for Prevention of Caries: A Review
}

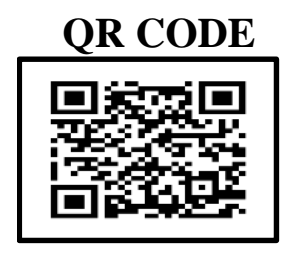

\section{MANSIMRANJIT KAUR UPPAL*}

Now a day's treatment modalities regarding dental caries have been changed with aim at maximum conservation of tooth structure and it's an ethical duty of a dentist to provide their patients with minimally invasive treatment. Remineralization therapy is preferred in cases, where there is a chance of gaining success by preventive methods. Many novel caries preventive materials are now available in the market which contains components that have the ability to initiate remineralization.

KEYWORDS: Dental Caries, Prevention, Treatment, Remineralization, Demineralization, Agents

\section{INTRODUCTION}

Dental caries and periodontal diseases are the one of common oral diseases and dental cares remains the most prevalent chronic childhood disease worldwide. "Dental caries is an irreversible microbial disease of the calcified tissues of the teeth, characterized by demineralization of the inorganic portion and destruction of the organic substance of the tooth, which often leads to cavitations. ${ }^{1}$

Dental caries is a peculiarly local disease which involves destruction of the hard tissues of the teeth by metabolites produced by oral microorganisms and management was based upon this concept only in the past time unless there was surgical/restorative intervention.2 In order to overcome many of the management related problems, modern treatment modalities should involve early detection of noncavitated lesions with individual's risk for caries progression. Even the detailed understanding of the caries process along with "active surveillance" is required to apply preventive measures for caries. ${ }^{2,3,4}$

Caries management protocols further refine the decisions concerning individualized treatment and its thresholds based on a specific patient's risk levels, age, and compliance with preventive strategies. Such protocols should yield greater probability of success and better cost effectiveness of treatment than less standardized treatment. Even the caries management protocols standardize the decision making and treatment strategies with stability in treatments and further eliminate various kinds of uncertainties in treatment procedures, and guarantee the more correct strategies. ${ }^{5,6}$
Currently management strategies are more focus on non-destructive and conservative approaches rather than restorative treatment alone along with many changes in understanding of the multifaceted nature of caries process and its management. We can describe the caries process as a dynamic balance between re- and demineralization, and if more minerals are lost than gained from the hard tissues over time, a lesion occurs as a sign of the disease. Among many of the persons demineralization and remineralization happen simultaneously in the oral cavity and carious lesions progression depends upon it. ${ }^{7,8}$ Therefore, any factor that can push this balance toward the proceeding of remineralization can be utilized as a weapon in the battle against dental caries. Hence an attempt has been made through this review where several novel therapeutic developments for the prevention of dental caries has been discussed which can be carried out by the individual dentist and are bound to change as treatment modalities evolve in future. ${ }^{9}$

Silver Diamine Fluoride: As its been said and proved that dental caries is process result from bacterial process and Silver Diamine Fluoride is the one of the successful agent which kills cariogenic bacteria by arresting of caries through precipitation on dentinal carious lesion. Not only this it can be also be used to promote remineralisation of hydroxyapatite which is a tooth mineral under constant acidic environment in the oral cavity. Even it is also in applicable in young children in case of management of dental caries, for further arrest of root caries, to prevent pit and fissure caries, to 
prevent secondary caries, to desensitise sensitive teeth, to treat infected root canals and to prevent the fracture of endodontically treated teeth..$^{10,11}$

Sodium Bicarbonate Chewing Gum: Various kind of researches has explained that regular use of sodium bicarbonate through toothpastes is very effective in reducing volatile sulphur compounds (VSCs) and thus altering the halitosis /oral malodour. Chewing gum would also be suspected of providing benefits in controlling oral malodour through its claimed ability to mechanically aid in the removal of dental plaque which will reduce the chances of occurrences of dental caries. ${ }^{12}$

Klaber et al. ${ }^{11}$ in 2001 did a human clinical study was to determine whether a commercial chewing gum containing 5\% sodium bicarbonate(The Baking Soda Gum [AHDC]) was effective in removing dental plaque when used as a supplement to regular tooth brushing by children. The bicarbonate gum demonstrated significant plaque reduction in all other areas of the mouth, even on tooth surfaces not directly contacted during chewing. Compliance with the chewing gum regimen was excellent, and oral health exams did not indicate any adverse events among children using either the chewing gum or mint tablets

Enamelon technology: The Enamelon technology is based on unstabilized amorphous calcium phosphate (ACP). Through this technology calcium salt like calcium sulphate and a phosphate salt such as ammonium phosphate are delivered separately to the patients intraorally with the help of dual chamber device. ${ }^{13}$ The salts mix with saliva \& dissolve releasing calcium and phosphate ions and results in immediate precipitation of $\mathrm{ACP}$ or (in the presence of fluoride ions) amorphous calcium fluoride phosphate (ACFP). ${ }^{14}$

NovaMin commercial product: There are various kinds of commercial products such as calcium sodium phosphosilicate and NovaMin which are readily available in the market are X-PUR toothpaste where sodium ions help to increase oral $\mathrm{pH}$ and decrease acidity in the oral cavity. Calcium sodium phosphosilicate forms a layer on the tooth surface that is structurally similar to natural enamel. X-PUR is recommended as a toothpaste application, but can also be used in medication carriers for longer exposure because it does not contain fluoride. ${ }^{5,16}$

The other products containing NovaMin include a homecare toothpaste from Natural Health Organics (Oravive ${ }^{\circledR}$ Revitalizing Paste- 5 wt\%, which does not contain fluoride), prescription pastes for hypersensitivity marketed by $3 \mathrm{M} / \mathrm{Omni}$ (SootheRx) and (Denshield ${ }^{\circledR}$ - both with 7.5 wt\%), and a prophypaste promoted by Sunstar/Butler (NuCare ${ }^{\circledR}$ $100 \mathrm{wt} \%$ and water). Newer products include a tooth root desensitizer (Vitalmin -10o wt\% NovaMin and water), a fluoride varnish (Durashield - $10 \mathrm{wt} \%$ NovaMin and $5 \% \mathrm{NaF}$ ), and a dentifrice (Renew 5000 ppm fluoride and $5 \mathrm{wt} \%$ NovaMin). ${ }^{14,15}$

\section{CONCLUSION}

Though many of the treatment strategies are available for dental caries but still preservation of tooth structure is not possible among many of the people. So there should be individualized consideration of the underlying disease process is recommended for every patient and minimal intervention program can be considered for high-risk patients. Hence this novel approach is based on research, clinical expertise, and the patient's preferences and individual needs, implementation of this new protocol will provide ultraconservative tooth preservation that gives good patient care.

\section{REFERENCES}

1. Rajendran R, Shivapathasundharam B, Raghu AR. Shafer's textbook of oral pathology. Shafer, Hine, Levy eds. $6^{\text {th }}$ ed. Noida, India: Elsevier 2005.

2. Bader JD, Shugars DA. What do we know about how dentists make caries-related treatment decisions? Com-munity Dent Oral Epidemiol 1997;25(1):97-103.

3. Ramos-Gomez F, Ng MW. Into the future: keeping healthy teeth caries free: pediatric CAMBRA protocols. J Calif Dent Assoc. 2011;39(10):723-33.

4. Young D, Ricks CS, Featherstone JD, et al. Changing the face and practice of dentistry: a 10year plan. J Calif Dent Assoc. 2011;39(10):746-51

5. White BA, Maupome G. Clinical decision-making for dental caries management. J Dent Ed 2001;65(10):1121-5.

6. Featherstone JD, Domejean-Orliaguet S, Jenson L, et al. Caries risk assessment in practice for age 6 through adult. J Calif Dent Assoc 2007;35(10):703-13. 
7. Domejean-Orliaguet S, Gansky SA, Featherstone JD. Caries risk assessment in an educational environment. J Dent Educ 2006;70(12):1346-54.

8. Young DA, Kutsch VK, Whitehouse J. A clinician's guide to CAMBRA: a simple approach. Compend Contin Educ Dent. 2009;30(2):924-8.

9. Steinberg S. Adding caries diagnosis to caries risk assessment: The next step in caries management by risk assessment (CAMBRA). Compend Contin Educ Dent. 2009;30(8):522, 524-6, 528

10. Chu $\mathrm{CH}$, Lo EC. Promoting caries arrest in children with silver diamine fluoride: a review. Oral Health Prev Dent. 20o8;6(4):315-21.

11. Klaber CJ, Davidson KR, Rhoades ML. An evaluation of sodium bicarbonate chewing gum as a supplement to tooth brushing for removal of dental plaque from children's teeth. Compend Contin Educ Dent. 2001 Jul;22(7A):36-42.

12. Soderling E, Hirvonen A, Karjalainen S, Fontana M, Catt D, Seppa L. The effect of xylitol on the composition of the oral flora: a pilot study. Eur J Dent. 2011;5(1):24-31.

13. Kallar S, Pandit IK, Srivastava N, Gugnani N. Plaque removal efficacy of powered and manual toothbrushes under supervised and unsupervised conditions: a comparative clinical study. J Indian Soc Pedod Prev Dent. 2011;29(3):235-8.

14. Reisine S, Douglass JM. Psychosocial and behavioural issues in early childhood caries. Community Dent Oral Epidemiol. 1998;26(suppl 1):32-44.

15. Souza DC, Hashizume LN, Eidelwein M, Maltz M. Effect of different frequencies of fluoride dentifrice and mouthrinse administration: an in situ study. Braz Oral Res. 2010;24(4):388-93.

16. Klaber CJ, Davidson KR, Rhoades ML. An evaluation of sodium bicarbonate chewing gum as a supplement to tooth brushing for removal of dental plaque from children's teeth. Compend Contin Educ Dent. 2001 Jul;22(7A):36-42.

Source of support: Nil, Conflict of interest: None declared

Cite this article as:

Uppal MK. Novel Agents for Prevention of Caries: A Review. Int Healthc Res J. 2019;2(12):304-306. doi: 10.26440/IHRJ/0212.03.521058

\section{AUTHOR AFFILIATIONS:}

MDS (Oral Medicine and Radiology), Private practitioner and consultant dental surgeon

*Corresponding Author:

Dr. Mansimranjit Kaur Uppal

H. no 401, Tower 10

Grand Forte Society

Sigma 4, Greater Noida 201310
For article enquiry/author contact details, e-mail at:editor.ihrj@gmail.com 